\title{
Biology of Brinjal Shoot and Fruit Borer
}

\author{
K.M. Bhoya and C.J. Patel* \\ Navsari Agricultural University, Navsari-396 450 (Gujarat), India \\ *Corresponding author
}

\section{Keywords \\ Biology, Brinjal, Shoot and fruit borer, Luecinodes orbonalis \\ Article Info \\ Accepted: \\ 18 October 2018 \\ Available Online: \\ 10 November 2018}

\section{A B S T R A C T}

The biology of brinjal shoot and fruit borer, Luecinodes orbonalis Guenee was studied in the Biocontrol laboratory, Department of Agricultural Entomology, N. M. College of Agriculture, Navsari Agricultural University, Navsari, Gujarat during 2016-17. The eggs of brinjal shoot and fruit borer were elongated and oval with creamy white colour. The incubation period ranged from 2 to 3 days $(2.36 \pm 0.49$ days $)$ while, hatchability was 60.0 per cent. The colour of neonate larva was dirty white whereas, full grown larva was pinkish brown in colour. Larvae passed through five distinct instars. The duration of first, second, third, fourth and fifth instar larva was $1.00 \pm 0.00,1.06 \pm 0.25,1.73 \pm 0.44,2.66 \pm$ 0.47 and $3.53 \pm 0.50$ days, respectively. Average length of first to fifth instars larva was $0.85 \pm 0.01,2.01 \pm 0.07,4.04 \pm 0.85,8.09 \pm 0.79$ and $14.64 \pm 1.26 \mathrm{~mm}$, whereas, average breadth was $0.16 \pm 0.01,0.39 \pm 0.05,1.01 \pm 0.04,1.80 \pm 0.29$ and $2.97 \pm 0.24 \mathrm{~mm}$, respectively. The total larval period was completed in $10.00 \pm 0.69$ days. The average prepupal and pupal period was $1.30 \pm 0.46$ and $5.76 \pm 0.77$ days, respectively. The adult moth was white in colour with blackish brown head and thorax. The abdomen of female was swollen and seemed to be ovate in structure with abdomen tip tapering and pointed towards the end whereas, in the males, it was thinner, cylindrical and blunt. The average fecundity of the female recorded $126.66 \pm 2.87$ eggs. Longevity of female was $4.61 \pm 0.50$ days while that of male was $2.33 \pm 0.49$ days. The total life cycle occupied 22 to 28 days ( $24.11 \pm 1.84$ days) by female and 20 to 26 days ( $21.66 \pm 2.22$ days) by male.

\section{Introduction}

Solanaceous vegetable crop Brinjal (Solanum melongena L.) is very popular and widely grown in India throughout the year. Main constrain is the attack of shoot and fruit borer and is a major pest of brinjal causing heavy damage and considered a limiting factor in brinjal cultivation. In Gujarat, the pest has been reported to inflict losses to the tune of upto 80 per cent (Jhala et al., 2003). The pest can be easily controlled by targeting on weakest life stage. Hence keeping the above points in view, the present investigation on biological studies was under taken to know the developmental aspects of life of shoot and fruit borer under laboratory conditions and also the weakest link in its life cycle at which the pest can be effectively controlled. 


\section{Materials and Methods}

\section{Rearing techniques}

The biology of brinjal shoot and fruit borer was studied under laboratory condition at 26.52 to $34.10{ }^{\circ} \mathrm{C}$ temperature and 30 to $50 \%$ relative humidity. Larvae collected from damaged fruits from unsprayed brinjal cv. GOAB-2 crop were utilized to obtain initial culture and the brinjal fruits having larvae were kept in plastic tray. To maintain sufficient aeration in the tray and to prevent the larvae escaping from the tray, the bottom of tray covered with papers and top open portion of the tray was covered with a piece of muslin cloth fixing with rubber band. The cocoons formed in the tray were transferred to glass jar for emergence of the adults.

Newly emerged moths were released in the oviposition cage $(20 \mathrm{~cm}$ diameter $\mathrm{x} 45 \mathrm{~cm}$ height) for mating. A tender shoots of brinjal having three to four tender leaves, cut ends of which was dipped in fresh water filled in conical flask to maintain turgidity of the shoots. The conical flask with these shoots was kept inside the oviposition cage for resting and oviposition of adults. A Cotton swab dipped in five per cent honey solution was placed in oviposition cage as a food for moths. The eggs were collected from the leaf, shoots and collected eggs were used for further study.

\section{Developmental stage}

Colour, shape and size of egg was determined with the help of Stereo Trinocular microscope Olympus-SZ (16) fitted with Brand Catcam130 camera having software power Scopephoto for measuring the size of egg.

For study the hatching percentage, the eggs laid on the same day were picked up with the help of fine camel hair brush and ten eggs were placed in one petri dish with set of thirty petri dishes. The observation on number of eggs hatched was recorded daily in the morning till unhatched eggs were shrinked. For incubation period, thirty eggs were examined from date of egg laying to the date of hatching.

With a view to determine the number and duration of different larval instars and total larval period, the thirty ( 2 set of fifteen) newly hatched larvae ware placed individually on a piece of brinjal fruit $\left(2 \times 2 \mathrm{~cm}^{2}\right)$ with the help of a fine camel hair brush in plastic culture tube. The piece of brinjal fruit in each tube was changed daily in the morning and the developing larva from the old piece was transferred to a fresh piece. Larvae were examined daily and change of instar was confirmed by presence of casted head capsule and sometimes exuviae in the rearing tube. The duration of each instar was worked out and measured.

To record the pre-pupal period, the larvae were observed from the time, when it came out from the fruit piece, stopped feeding and became sluggish to the time when it was turned to pupa. Freshly formed pupae were collected and kept individually in plastic tubes.

The moths emerged were separated as male and female confirming by the presence of pointed and curl upward abdomen at resting time in case of female, which was blunt in male. The both sexes of adult moth were observed for their colour and size. One pair of male and female moth of the same age group was paired separately in oviposition cage to study their longevity of adults and fecundity. The length and breadth of their expanded wings were also measured with the help of scale. The period, in day from date of egg laid to the date of adult died is considered as total life cycle. 


\section{Results and Discussion}

\section{Egg}

In laboratory, it was observed that, the female moth of shoot and fruit borer laid eggs singly or in batches of 2 to 3 eggs. The eggs were glued on tender leaves on both the surface as well as on shoots. Earlier, similar pattern of egg laying was noticed by Wankhede et al., (2009) and Maravi et al., (2013).

The colour of freshly laid eggs was creamy white. Before hatching it changed to orange with a prominent block spot. Eggs were elongated and oval in shape. The present observation is similar with that of Wankhede et al., (2009) and Maravi et al., (2013).

Total thirty eggs of one day old age were examined under the Stereo Trinocular microscope Olympus-SZ (16) fitted with Brand Catcam-130 camera having software power Scopephoto for measuring their size and shape. The result presented in Table 1 revealed that, average length of eggs was 0.61 $\pm 0.05 \mathrm{~mm}$ with minimum and maximum length of 0.44 and $0.69 \mathrm{~mm}$, respectively. Similarly, an average breadth of eggs was 0.33 $\pm 0.03 \mathrm{~mm}$ with minimum and maximum breadth of 0.21 and $0.36 \mathrm{~mm}$, respectively. The present result is almost similar with that of Kumar et al., (2003) who reported the length and breadth of egg as an average $0.48 \pm$ 0.06 and $0.54 \pm 0.03 \mathrm{~mm}$, respectively.

Out of 300 observed eggs under laboratory conditions, 180 eggs were found to hatch and thus the hatchability was calculated to an extent of $60.00 \pm 0.64$ per cent (Table 1). The present result is very close to that of Mannan et al., (2015) who observed 60.80 per cent hatching.

An incubation period of eggs of brinjal shoot and fruit borer varied from 2 to 3 days with an average of $2.36 \pm 0.49$ days. The average incubation period for eggs of shoot and fruit borer has been reported as 3.49 days (Maravi et al., 2013) which is in close concurrence with present finding.

\section{Larva}

The neonate larvae were usually dirty white in colour. As the stage advanced colour changed from dirty white to pink colour. Larva of other stages was pinkish brown in colour and head was brown to chestnut brown in colour. Similar observations regarding larval colour were noticed by Maravi et al., (2013) and Bindu et al., (2015).

In order to study the various larval instar of brinjal shoot and fruit borer under laboratory condition, newly hatched larvae were reared individually in plastic culture tube. A change of instar was confirmed by presence of casted head capsule and sometimes exuviae in the rearing tube. It was observed that in all the cases, the larvae passed through five distinct instars, when reared on fresh piece of brinjal fruits, till they pupated. Kumar et al., (2003) also recorded five instars in shoot and fruit borer reared on brinjal while, Maravi et al., (2013) recorded six instar.

The data presented in Table 2 revealed that the length of first instar larva measured in range of 0.82 to $0.88 \mathrm{~mm}$ (Av. $0.85 \pm 0.01 \mathrm{~mm}$ ) and the breadth varied from 0.14 to $0.20 \mathrm{~mm}$ (Av. $0.16 \pm 0.01)$. The report is almost similar to that of average length $0.86 \pm 0.02 \mathrm{~mm}$ and breadth $0.13 \pm 0.01 \mathrm{~mm}$ reported by Kumar et al., (2003). Bindu et al., (2015) have measured on an average $2.03 \pm 0.36 \mathrm{~mm}$ in length and $0.26 \pm 0.05 \mathrm{~mm}$ breadth

As far as duration of first instar is concerned, it was observed to be of one day (Table 3). Similar report of one day duration of first instar larva was noted by Onekutu et al., 
(2013). Kumar et al., (2003) also reported 1.40 days of first instar larval period. However, Bindu et al., (2015) reported on an average of $2.6 \pm 0.55$ days of duration of first instar larva.

The larval measurement in second instar larva was ranged from 1.92 to $2.09 \mathrm{~mm}$ (Av. $2.01 \pm$ $0.07 \mathrm{~mm}$ ) in length and 0.32 to $0.45 \mathrm{~mm}$ (Av. $0.39 \pm 0.05 \mathrm{~mm}$ ) in breadth (Table 2). Bindu et al., (2015) recorded the average larval length of $4.00 \pm 0.30 \mathrm{~mm}$ and breadth of 0.70 $\pm 0.13 \mathrm{~mm}$, which was quite double in size to measured in present study.

The duration of second instar larva ranged from 1 to 2 days with an average of $1.06 \pm$ 0.25 days (Table 3 ). The present report is almost similar to that of reported an average of 1.82 days by Kumar et al., (2003). Bindu et al., (2015) recorded the average second instar larval period of $2.8 \pm 0.71$ days.

The length of third instar larva (Table 2) varied from 3.23 to $5.32 \mathrm{~mm}$, while that of the breadth was varied from 0.95 to $1.08 \mathrm{~mm}$. The average length and breadth of third instar larva was recorded to be $4.04 \pm 0.85$ and $1.01 \pm$ $0.04 \mathrm{~mm}$, respectively. The present findings are not comply with the finding of Bindu et al., (2015) who reported the average length and breadth of third instar larva of shoot and fruit borer to be $8.03 \pm 0.64 \mathrm{~mm}$ and $1.48 \pm$ $0.20 \mathrm{~mm}$, respectively.

The duration required to complete third instar larva (Table 3) was 1 to 2 days (Av. $1.73 \pm$ 0.44 days). This finding is supported by Onekutu et al., (2013) who had also found the similar result i.e., 1.48 days period but quite differ with report of Kumar et al., (2003) and Bindu et al., (2015) who reported 2.15 and 3.2 \pm 0.84 days, respectively.

The data on measurement presented in Table 2 indicated that the length of fourth instar larva was ranged from 7.37 to $9.31 \mathrm{~mm}$ (Av. $8.09 \pm$ $0.79 \mathrm{~mm}$ ), whereas breadth was ranged from 1.53 to $2.15 \mathrm{~mm}$ (Av. $1.80 \pm 0.29 \mathrm{~mm}$ ). Bindu et al., (2015) reported $11.74 \pm 0.46 \mathrm{~mm}$ average body length and $2.13 \pm 0.39 \mathrm{~mm}$ breadth.

As far as duration of fourth instar larva is concerned (Table 3), it was observed from 2 to 3 days with an average of $2.66 \pm 0.47$ days. The present findings are more or less in confirmation with that of Onekutu et al., (2013) and Kumar et al., (2003) who reported as an average 2.63 and 2.72 day, respectively. However, Bindu et al., (2015) reported $3.4 \pm$ 0.89 days larval period.

The length and breadth of fifth instar larva (Table 2) was ranged from 13.18 to $16.27 \mathrm{~mm}$ (Av. $14.64 \pm 1.26 \mathrm{~mm}$ ) and 2.73 to $3.28 \mathrm{~mm}$ (Av. $2.97 \pm 0.24 \mathrm{~mm}$ ), respectively. Previously, it was reported the length and breadth of fifth instar larva as $17.30 \pm 1.1 \mathrm{~mm}$ and $3.92 \pm 0.35 \mathrm{~mm}$, respectively by Bindu et al., (2015).

Larval duration of fifth instar larva varied from 3 to 4 days with an average of $3.53 \pm$ 0.50 days (Table 3). The report is almost similar to that of reported as 3.47 days by Kumar et al., (2003).

The present investigation supported more or less similar confirmation with Onekutu et al., (2013) who recorded duration of fifth instar larva as an average of 4.46 days. However, Bindu et al., (2015) reported only $2.8 \pm 0.55$ days duration.

The perusal of data presented in Table 3 revealed that the total larval development period of shoot and fruit borer varied from 9 to 11 days with an average of $10.00 \pm 0.69$ days. Allam et al., (1982) reported 9 to 13 days larval period which is more or less similar to present finding. 


\section{Pupa}

The fifth instar larvae of shoot and fruit borer left the fruit piece and, stop the feeding and become sluggish. Finally larvae start secreting a silk cocoon for pupation.

The length and breadth of pre-pupa was found varied from 17.62 to $19.17 \mathrm{~mm}$ (Av. $18.29 \pm$ $0.58 \mathrm{~mm}$ ) and 2.72 to $3.75 \mathrm{~mm}$ (Av. $2.97 \pm$ $0.26 \mathrm{~mm}$ ) as presented in Table 4. The prepupal period was ranged from 1 to 2 days (Av.
$1.30 \pm 0.46$ days) during present study. The result is very close comply with result of Yadav et al., (2015) who reported average pre-pupal period of $1.60 \pm 0.20$ and $1.40 \pm$ 0.20 days in two seasons.

The pre-pupa found its way for pupation which in laboratory conditions took place at the bottom of the plastic tube or inside the top of the lid or on paper which provided in tube where cocoon formed and changed into pupa. Pupa had dark brown in colour.

Table.1 Measurement of egg of brinjal shoot and fruit borer

\begin{tabular}{|l|c|c|c|}
\hline Particulars & Min. & Max. & Av. \pm S.D \\
\hline Length $(\mathbf{m m})$ & 0.44 & 0.69 & $0.61 \pm 0.05$ \\
\hline Width $(\mathbf{m m})$ & 0.21 & 0.36 & $0.33 \pm 0.03$ \\
\hline Incubation period (days) & 2 & 3 & $2.36 \pm 0.49$ \\
\hline Hatching Percentage & 50 & 70 & $60.00 \pm 0.64$ \\
\hline
\end{tabular}

Table.2 Measurement of different larval instars of brinjal shoot and fruit borer

\begin{tabular}{|c|c|c|c|c|c|c|c|c|c|c|}
\hline Instars & \multicolumn{2}{|c|}{$1^{\text {st }}$ instar } & \multicolumn{2}{|c|}{$2^{\text {nd }}$ instar } & \multicolumn{2}{|c|}{$3^{\text {rd }}$ instar } & \multicolumn{2}{|c|}{$4^{\text {th }}$ instar } & \multicolumn{2}{|c|}{$5^{\text {th }}$ instar } \\
\hline & $\mathbf{L}$ & B & $\mathbf{L}$ & B & $\mathbf{L}$ & B & $\mathbf{L}$ & B & $\mathbf{L}$ & B \\
\hline Min. & 0.82 & 0.14 & 1.92 & 0.32 & 3.23 & 0.95 & 7.37 & 1.53 & 13.18 & 2.73 \\
\hline Max. & 0.88 & 0.20 & 2.09 & 0.45 & 5.32 & 1.08 & 9.31 & 2.15 & 16.27 & 3.28 \\
\hline $\begin{array}{c}\text { Av. } \pm \\
\text { S.D }\end{array}$ & $\begin{array}{c}0.85 \pm \\
0.01\end{array}$ & $\begin{array}{c}0.16 \\
\pm 0.01\end{array}$ & $\begin{array}{c}2.01 \\
\pm 0.07\end{array}$ & $\begin{array}{c}0.39 \\
\pm 0.05\end{array}$ & $\begin{array}{c}4.04 \\
\pm 0.85\end{array}$ & $\begin{array}{c}1.01 \\
\pm 0.04\end{array}$ & $\begin{array}{l}8.09 \\
\pm 0.79\end{array}$ & $\begin{array}{l}1.80 \\
\pm 0.29\end{array}$ & $\begin{array}{l}14.64 \\
\pm 1.26\end{array}$ & $\begin{array}{l}2.97 \\
\pm 0.24\end{array}$ \\
\hline
\end{tabular}

$\mathrm{L}=$ Length, $\mathrm{B}+$ Breadth

Table.3 Duration of different larval instars of shoot and fruit borer

\begin{tabular}{|c|c|c|c|c|c|c|}
\hline & \multicolumn{5}{|c|}{ Duration of different larval instar (days) } & \multirow[t]{2}{*}{ Total larval period } \\
\hline & $\begin{array}{c}1^{\text {st }} \\
\text { instar }\end{array}$ & $\begin{array}{c}2^{\text {nd }} \\
\text { instar }\end{array}$ & $\begin{array}{c}\mathbf{3}^{\text {rd }} \\
\text { instar }\end{array}$ & $\mathbf{4}^{\text {th }}$ & $\begin{array}{c}5^{\text {th }} \\
\text { instar }\end{array}$ & \\
\hline Min. & 1 & 1 & 1 & 2 & 3 & 9 \\
\hline Max. & 1 & 2 & 2 & 3 & 4 & 11 \\
\hline Av. \pm S.D & $1 \pm 0$ & $1.06 \pm 0.25$ & $1.73 \pm 0.44$ & $2.66 \pm 0.47$ & $3.53 \pm 0.50$ & $10.00 \pm 0.69$ \\
\hline
\end{tabular}


Table.4 Measurement and duration of pre-pupa and pupa of brinjal shoot and fruit borer

\begin{tabular}{|l|c|c|c|}
\hline \multicolumn{1}{|c|}{ Particulars } & Min. & Max. & Av. \pm S.D \\
\hline Pre-pupa & & & \\
\hline Length (mm) & 17.62 & 19.17 & $18.29 \pm 0.58$ \\
\hline Breadth (mm) & 2.72 & 3.75 & $2.97 \pm 0.26$ \\
\hline Pupa & & & \\
\hline Length (mm) & 10.97 & 13.09 & $12.10 \pm 0.88$ \\
\hline Breadth (mm) & 5.01 & 7.45 & $5.84 \pm 0.91$ \\
\hline Pre-pupal period (days) & 1 & 2 & $1.30 \pm 0.46$ \\
\hline Pupal period (days & 5 & 7 & $5.76 \pm 0.77$ \\
\hline
\end{tabular}

Table.5 Measurement and longevity of brinjal shoot and fruit borer

\begin{tabular}{|c|c|c|}
\hline Particulars & Range & Av. \pm SD \\
\hline Male adult & & \\
\hline Length (mm) & $8.53-8.88$ & $8.72 \pm 0.16$ \\
\hline Breadth (mm) & $2.23-2.60$ & $2.42 \pm 0.16$ \\
\hline Wingspan (mm) & $19.92-20.05$ & $19.98 \pm 0.05$ \\
\hline Female adult & & \\
\hline Length (mm) & $9.73-10.05$ & $9.84 \pm 0.12$ \\
\hline Breadth (mm) & $3.50-3.99$ & $3.75 \pm 0.14$ \\
\hline Wingspan (mm) & $20.97-26.09$ & $24.15 \pm 1.48$ \\
\hline Longivity (days) & $2-3$ & \\
\hline Male & $4-5$ & $4.33 \pm 0.49$ \\
\hline Female & & \\
\hline Total life span (days) & $20-26$ & $21.66 \pm 2.22$ \\
\hline Male & $22-28$ & $24.11 \pm 1.84$ \\
\hline Female & $122-132$ & $126.6 \pm 2.87$ \\
\hline Fecundity
\end{tabular}

The length of pupa was measured from 10.97 to $13.09 \mathrm{~mm}$ (Av. $12.10 \pm 0.88 \mathrm{~mm}$ ), while that of breadth was measured from 5.01 to $7.45 \mathrm{~mm}$ (Av. $5.84 \pm 0.91 \mathrm{~mm})$. The present investigation is more or less similar with Bindu et al., (2015) in case of pupal length only, who recorded as an average length 12.34 $\pm 1.67 \mathrm{~mm}$ but the breadth measurement was quite varied i.e., $4.40 \pm 0.47 \mathrm{~mm}$. The pupal period varied from 5 to 7 days with an average of $5.76 \pm 0.77$ days (Table 4).

\section{Adult}

Adults were emerged from pupa during the night hours. During the day time adults remained inactive on the lower surface of the host leaf and were not usually seen. They were found to be active at night for their mating and oviposition purposes. The adult moth was white in colour with blackish brown head and thorax. The forewings were white with pinkish brown markings. Hind wings were dirty white with black dots. The adult female was larger 
than male, by abdominal characteristics and wider wingspan. The abdomen of female was swollen and seemed to be ovate in structure whereas, in the males, it was thinner and cylindrical. The abdominal tip of females was tapering and pointed towards the end whereas; in males it was blunt with white hairy structures.

The length of adult female varied from 9.73 to $10.05 \mathrm{~mm}$ (Av. $9.84 \pm 0.12 \mathrm{~mm}$ ) and the breadth varied from 3.50 to $3.99 \mathrm{~mm}$ (Av. $3.75 \pm 0.14 \mathrm{~mm}$ ) (Table 5). Whereas, in case of male, the length varied from 8.53 to 8.88 $\mathrm{mm}$ (Av. $8.72 \pm 0.16 \mathrm{~mm}$ ) and the breadth varied from 2.23 to $2.60 \mathrm{~mm}$ (Av. $2.42 \pm 0.16$ $\mathrm{mm})$. The wingspan of female varied from 20.97 to $26.09 \mathrm{~mm}$ (Av. $24.15 \pm 1.48$ ). Whereas, in case of male it was from 19.92 to $20.05 \mathrm{~mm}$ (Av. $19.98 \pm 0.05 \mathrm{~mm}$ ). The present investigation provide more or less similar confirmation with report of Bindu et al., (2015) who recorded average length, breadth and wingspan of female as $14.53 \pm$ $1.23,4.41 \pm 1.33$ and $23.41 \pm 1.45$ and in male $13.54 \pm 2.12,2.98 \pm 0.38$ and $20.55 \pm$ 1.41 , respectively.

The longevity (Table 5) of female ranged from 4 to 5 days $(4.61 \pm 0.50$ days $)$ while male lived for 2 to 3 days $(2.33 \pm 0.49$ days). Yadav et al., (2015) also recorded little bit the same tune of longevity of female and male adult. Thus, longevity of male was shorter than female recorded during present investigation

Under laboratory condition, the egg laying capacity recorded during the study was varied from 122 to 132 eggs $(126.66 \pm 2.87 \mathrm{eggs})$ per female. Previously, very close results were also reported by Wankhede et al., (2009).

The total life span (Table 5) from eggs to the death of male moth was ranged from 20 to 26 day (Av. $21.66 \pm 2.22$ day) while for female moth was ranged from 22-28 day (Av. 24.11 \pm 1.84 day). This observation on total life cycle was almost similar to the observations recorded by Kumar et al., (2003) who recorded an average life span for two season that was $21.90 \pm 3.81$ and $22.10 \pm 3.57$ day for male whereas $23.80 \pm 4.21$ and $25.20 \pm$ 4.21 day for female.

The incubation, larval, pre-pupal and pupal periods were found to be $2.36 \pm 0.49,10.00 \pm$ $0.69,1.3 \pm 0.46$ and $5.76 \pm 0.84$ days, respectively. Life span of male and female moth was $21.66 \pm 2.22$ and $24.11 \pm 1.84$ days, respectively. The longevity of male and female was $2.33 \pm 0.49$ and $4.61 \pm 0.50$ days Female laid an average $126.6 \pm 2.87$ eggs. Hatching percentage was $60.00 \pm 0.64$.

\section{References}

Allam, M. A., Rao, P. K. and Rao, B. H. K. (1982). Biology of brinjal shoot and fruit borer, Leucinodes orbonalis Guen. Indian Journal of Agricultural Science, 52(6): 391-395.

Bindu, S. P., Pramanik, A. and Padhi, G. K. (2015). Studies on biology and physical measurements of shoot and fruit borer (Leucinodes orbonalis guenee) of brinjal in west bengal, india. Global Journal of Biology, Agriculture and Health Science, 4 (1): 215-219.

Jhala, R. C., Patel, M. G., Chanda, A. J. and Patel Y. C. (2003). Testing IPM strategy for Leucinodes orbonalis in farmers field. Proceedings of National Symposium on frontiers of Entomological Research, New Delhi, Nov, 5-7, pp: 256.

Kumar, V. A., Nagangoud, A., Patil, B. V. (2003). Biology of brinjal shoot and fruit borer Leucinodes orbonalis Guen. Pest management in horticultural ecosystem., 9 (2): 127-131. 
Mannan, M. A., Islam, K. S., Jahan, M. and Tarannam, N. (2015). Some biological parameters of brinjal shoot and fruit borer, Leucinodes orbonalis guenee (Lepidoptera: Pyralidae) on potato in laboratory condition. Bangladesh $J$. Agril. Res., 40 (3): 381-390.

Maravi, M. S., Dubey, V. K. and Paikra, M. K. (2013). Biology of Leucinodes orbonalis Guen. on Brinjal (Solanum melongena) crop. Indian Horticulture Journal, 3 (3/4): 91-94.

Onekutu, A., Omoloye, A. A. and Odebiyi, J.A. (2013). Biology of the fruit and Shoot Borer (EFSB), Luecinodes orbonalis Guenee (Crambidae) on the
Garden Egg, Solanum gilo Raddi. Journal of Entomology, 10 (3): 156162.

Wankhede, S. M., Kale, V. D. and Gangurde, S.M. (2009). Biology of Leucinodes orbonalis: An Important Pest of Brinjal. International Journal of Plant Protection, 2(2): 258-260.

Yadav, A., Sachan, S. K., Yadav, A. and Yadav, T. (2015). Biology of brinjal shoot and fruit borer, Leucinodes orbonalis g. under lab condition at $35^{\circ} \mathrm{C}$ temperature and $90 \%$ relative humidity during 2009 and 2010. Plant Archives, 15(2): 889-893.

\section{How to cite this article:}

Bhoya, K.M. and Patel, C.J. 2018. Biology of Brinjal Shoot and Fruit Borer. Int.J.Curr.Microbiol.App.Sci. 7(11): 2605-2612. doi: https://doi.org/10.20546/ijcmas.2018.711.297 